\title{
COMMENTARY
}

\section{Urinalysis and pre-renal acute kidney injury: time to move on}

\author{
Antoine G Schneider ${ }^{1,2,3}$ and Rinaldo Bellomo*1,2 \\ See related research by Pons et al., http://ccforum.com/content/17/2/R56
}

\begin{abstract}
Urinary indices are classically believed to allow differentiation of transient (or pre-renal) acute kidney injury (AKI) from persistent (or acute tubular necrosis) AKI. However, the data validating urinalysis in critically ill patients are weak. In the previous issue of Critical Care, Pons and colleagues demonstrate in a multicenter observational study that sodium and urea excretion fractions as well as urinary over plasma ratios performed poorly as diagnostic tests to separate such entities. This study confirms the limited diagnostic and prognostic ability of urine testing. Together with other studies, this study raises more fundamental questions about the value, meaning and pathophysiologic validity of the pre-renal AKI paradigm and suggests that AKI (like all other forms of organ injury) is a continuum of injury that cannot be neatly divided into functional (pre-renal or transient) or structural (acute tubular necrosis or persistent).
\end{abstract}

In textbook medicine, pre-renal acute kidney injury (AKI) is classically differentiated from other subtypes of AKI such as acute tubular necrosis (ATN) by means of urinary indices such as fractional excretion of sodium or urea. However, this approach has never been validated in critically ill patients.

In the previous issue of Critical Care, Pons and colleagues examine the diagnostic accuracy of early changes in several urinary indices to differentiate transient AKI from persistent AKI [1]. In a study in six centers and 244 critically ill patients, they assessed urinalysis against an objective, time-based definition for pre-renal (transient) AKI. In addition, the authors examined

${ }^{*}$ Correspondence: rinaldo.bellomo@austin.org.au

'Intensive Care Unit, Austin Health, 145 Studley Road, Heidelberg, Victoria 3084, Australia

Full list of author information is available at the end of the article dynamic changes in such indices by repeating measurements every 6 hours after ICU admission. Their results confirm the poor performance of urinary indices as diagnostic tools to separate transient AKI from persistent AKI in critical illness. This performance remained low even after exclusion of patients who received diuretics in the previous 6 hours and those with sepsis. The authors correctly conclude that urinary indices remain insufficiently reliable to be clinically relevant.

Numerous studies had observed the limited diagnostic or prognostic ability of urinary biochemistry [2-6]. Pons and colleagues confirmed these limits even when objective and verifiable criteria are used to define pre-renal AKI. Beyond the lack of utility of urinary diagnostic tests, this work highlights the absence of a universally accepted gold standard to define pre-renal AKI or transient AKI [7]. Without a gold standard for diagnosing a syndrome in a given patient, the performance of any diagnostic test is likely to be controversial. Indeed, the performance of early biomarkers of renal injury (such as urinary or plasma neutrophil gelatinase-associated lipocalin) to discriminate transient AKI from persisting AKI is also poor [8].

Altogether, the results presented by Pons and colleagues should make us question the whole paradigm of pre-renal AKI. Indeed, classically, pre-renal AKI is thought to represent situations of oliguria and azotemia associated with histologically intact nephrons. However, in the absence of a renal biopsy this concept remains purely theoretical. Similarly, there is no evidence that ATN is the histopathological substrate of nonresolving AKI. Early postmortem series in patients with sepsis with or without AKI revealed that renal tubular injury was common in all patients but presented focally and that most renal tubular cells appeared normal [9]. The actual existence of a histopathological lesion-free AKI can therefore be challenged as unrealistic and nonevidence based, at least in septic patients.

If histology and urinary biochemistry are unable to discriminate between these two entities, one possible logical explanation may be that they simply do not exist except in the mind of some physicians. A more pragmatic 
definition based on the duration of AKI is similarly problematic because determining the correct cutoff point to separate any two entities is impossible. Why choose 72 hours, not 24 or 48 hours? In a large epidemiological study (more than 3,000 AKI patients), Uchino and colleagues found that, compared with no AKI, the odds of dying in hospital increased by a factor of two in patients with transient ( $<3$ days) AKI and by a factor of six in those with persistent (>3 days) AKI [10]. However, the mortality increased with the duration of AKI without any particular cutoff point. Hence, like every other disease known to man, AKI seems to be a continuum and its duration, consequences and reversibility are more probably related to the severity and duration of the injury than to different pathophysiological mechanisms. Now is the time to let go of outdated and invalid concepts such as pre-renal AKI, transient AKI, or ATN that, in critically ill patients, have no supportive evidence.

In conclusion, Pons and colleagues' study is important because it confirms the limited diagnostic or prognostic ability of urinary biochemistry in critical care and also because it challenges the pre-renal AKI paradigm. Prerenal AKI and ATN probably do not exist in the way we classically conceptualize them. It is time to move on.

\section{Abbreviations}

AKI, acute kidney injury; ATN, acute tubular necrosis.

\section{Competing interests}

The authors declare that they have no competing interests.

\section{Author details}

'Intensive Care Unit, Austin Health, 145 Studley Road, Heidelberg, Victoria 3084, Australia. ${ }^{2}$ Australian and New Zealand Intensive Care Research Centre, Monash University, 55 Commercial Road, Prahran, Victoria 3181 Australia. ${ }^{3}$ Intensive Care Unit, Centre Hospitalo-Universitaire Vaudois, 46 rue du Bugnon, 1011 Lausanne, Switzerland.
Published: 7 May 2013

\section{References}

1. Pons B, Lautrette A, Oziel J, Dellamonica J, Vermesh R, Ezingeard E, Mariat C, Bernardin G, Zeni F, Cohen Y, Tardy B, Souweine B, Vincent F, Darmon M: Diagnostic accuracy of early urinary index changes in differentiating transient from persistent acute kidney injury in critically ill patients: multicenter cohort study. Crit Care 2013, 17:R56.

2. Prowle J, Bagshaw SM, Bellomo R: Renal blood flow, fractional excretion of sodium and acute kidney injury: time for a new paradigm? Curr Opin Crit Care 2012, 18:585-592.

3. Bagshaw SM, Bennett M, Devarajan P, Bellomo R: Urine biochemistry in septic and non-septic acute kidney injury: a prospective observational study. J Crit Care 2012. [Epub ahead of print]

4. Claure-Del Granado R, Macedo E, Mehta RL: Urine microscopy in acute kidney injury: time for a change. Am J Kidney Dis 2011, 57:657-660.

5. Bagshaw SM, Langenberg C, Bellomo R: Urinary biochemistry and microscopy in septic acute renal failure: a systematic review. Am J Kidney Dis 2006, 48:695-705.

6. Langenberg C, Wan L, Bagshaw SM, Egi M, May CN, Bellomo R: Urinary biochemistry in experimental septic acute renal failure. Nephrol Dial Transplant 2006, 21:3389-3397.

7. Macedo E, Mehta RL: Prerenal failure: from old concepts to new paradigms. Curr Opin Crit Care 2009, 15:467-473.

8. Nickolas TL, Schmidt-Ott KM, Canetta P, Forster C, Singer E, Sise M, Elger A, Maarouf O, Sola-Del Valle DA, O'Rourke M, Sherman E, Lee P, Geara A, Imus P, Guddati A, Polland A, Rahman W, Elitok S, Malik N, Giglio J, El-Sayegh S, Devarajan P, Hebbar S, Saggi SJ, Hahn B, Kettritz R, Luft FC, Barasch J: Diagnostic and prognostic stratification in the emergency department using urinary biomarkers of nephron damage: a multicenter prospective cohort study. J Am Coll Cardio/ 2012, 59:246-255.

9. Takasu O, Gaut JP, Watanabe E, To K, Fagley RE, Sato B, Jarman S, Efimov IR, Janks DL, Srivastava A, Bhayani SB, Drewry A, Swanson PE, Hotchkiss RS: Mechanisms of cardiac and renal dysfunction in patients dying of sepsis. Am J Respir Crit Care Med 2013, 187:509-517.

10. Uchino S, Bellomo R, Bagshaw SM, Goldsmith D: Transient azotaemia is associated with a high risk of death in hospitalized patients. Nephrol Dial Transplant 2010, 25:1833-1839.

doi:10.1186/cc12676

Cite this article as: Schneider AG, Bellom R: Urinalysis and pre-renal acute kidney injury: time to move on. Critical Care 2013, 17:141. 